\title{
Effect of silencing TEM8 gene on proliferation, apoptosis, migration and invasion of XWLC-05 lung cancer cells
}

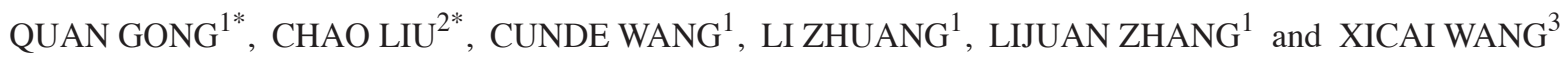 \\ Departments of ${ }^{1}$ Palliative Medicine and ${ }^{2}$ Nuclear Medicine, ${ }^{3}$ Tumor Research Institute, \\ Third Affiliated Hospital of Kunming Medical University, Kunming, Yunnan 650118, P.R. China
}

Received February 27, 2017; Accepted August 17, 2017

DOI: $10.3892 / \mathrm{mmr} .2017 .7959$

\begin{abstract}
Currently, the role of tumor endothelial marker 8 (TEM8) in the occurrence, development, invasion and metastasis of lung cancer and its mechanism are poorly understood. The present study aimed to investigate the effects of TEM8 on proliferation, apoptosis, migration and invasion of XWLC-05 lung cancer cells. The expression of TEM8 in human lung cancer and adjacent tissues was detected by reverse transcription-quantitative polymerase chain reaction and western blotting. An interference vector coding a short hairpin RNA (shRNA) targeting TEM8 was designed and transfected into XWLC-05 lung cancer cells. MTT assay was used to detect cell proliferation. Flow cytometry was employed to detect cell cycle and apoptosis. Cell scratch assay was used for cell migration detection. Cell invasion ability was detected by the Transwell method. The expression of TEM8 in lung cancer tissues was significantly increased compared with adjacent tissues $(\mathrm{P}<0.05)$. Following the silencing of TEM8 by shRNA interference, cell proliferation was inhibited and the apoptosis rate increased. The cell cycle was arrested at G1 phase, while the migration and invasion ability of cancer cells was decreased. Silencing TEM8 may inhibit proliferation of XWLC-05 lung cancer cells, promote cell apoptosis, arrest the cell cycle at G1 phase and decrease the migration and invasive ability. Thus, TEM8 may be a potential target in therapy for lung cancer.
\end{abstract}

\section{Introduction}

Lung cancer is one of the most prevalent malignant tumors, endangering health and life worldwide. Although the level

Correspondence to: Professor Xicai Wang, Tumor Research Institute, Third Affiliated Hospital of Kunming Medical University, 519 Kunzhou Road, Xishan, Kunming, Yunnan 650118, P.R. China E-mail: wangxc2005323@126.com

${ }^{*}$ Contributed equally

Key words: tumor endothelial marker 8, lung cancer, proliferation, apoptosis, invasion of medical care has been greatly improved, survival rates remain unsatisfactory $(1,2)$. Hematogenous metastasis is an important pathway of invasion and metastasis for malignancies. At present, anti-angiogenesis therapy is a common strategy for anti-tumor therapy. However, the efficacy of anti-angiogenic drugs is below expectations, and the overall survival rate is not significantly improved (3-5). As an example of a discouraging clinical evidence is the aggressive recurrence of tumors after withdrawal of anti-angiogenic treatment (6). Pa'ez-Ribes et al (7) has reported that although the anti-VEGFR2 antibody DC101 arrested tumor growth, at the same time it increases the rate of tumor invasion and metastasis. There are several reports focusing on the adverse effects of such treatments, such as bleeding, thrombotic events, and others (7-10). The majority of the well-known vascular endothelial markers are expressed in tumor and normal tissues with low specificity, which lead to a series of side effects, susceptibility to drug resistance and the recurrence of tumor growth following short-term administration (11-13). Therefore, finding specific molecular markers is urgently required to improve the efficacy of anti-angiogenic treatment.

The XWLC-05 lung cancer cell line is a human lung adenocarcinoma cell line established by Yan et al (14) and consistent with characteristics of lung adenocarcinoma cells, which is a good model for the invasion and metastasis of lung cancer in vitro. RNA interference may induce highly specific post-transcriptional silencing of genes, and its silencing efficiency is determined by the number and specificity of the transfection efficiency into target cells.

St Croix et al (15) identified a class of genes specifically expressed in tumor-derived vascular endothelial cells, called tumor endothelial markers (TEMs). TEM8 is a member of the TEM family with only a trace of expression in non-vascular endothelium and normal vascular endothelium, although it is highly expressed in tumor vascular endothelium (16). TEM8 is expressed on the surface of tumor vascular endothelial cells with high conservatism, indicating it may be a potential target in the anti-angiogenic therapy of cancer. Currently, the role of TEM8 in the occurrence, development, invasion and metastasis of lung cancer, and its mechanism are poorly understood. The present study observed the effect of TEM8 on the proliferation, apoptosis, cell cycle, migration and invasion of XWLC-05 lung cancer cells in vitro. The association between TEM8 and the biological behavior of 
lung cancer cells was investigated, laying the foundation for further exploration of the mechanism of TEM8 in lung cancer angiogenesis.

\section{Materials and methods}

Subjects. Human lung cancer tissues and adjacent tissues were obtained from 67 patients (57 males and 10 females, male to female ratio 5.7) having undergone lung cancer resection (37 cases with adenocarcinoma, 28 cases with squamous cell carcinoma and 2 cases with large cell carcinoma) in the Third Affiliated Hospital of Kunming Medical University (Kunming, China) between January 2010 and August 2015. All patients were diagnosed with lung cancer by two independent pathologists and were not treated with radiotherapy or chemotherapy prior to surgery. The mean age at diagnosis was 62.4 (standard deviation 5.7). Clinical data of all cases were obtained from the clinical medical history and pathological reports of patients. Written informed consents were obtained from the patients or their guardians. The study was approved by the Ethical Committee of the Third Affiliated Hospital of Kunming Medical University.

Cells. The XWLC-05 human lung adenocarcinoma cell line is archived by the Tumor Research Institute of the Third Affiliated Hospital of Kunming Medical University.

Main reagents and instruments. The following reagents and chemicals were used for the experiments: TEM8-short hairpin (sh)RNA interference vector and negative control (Shanghai GenePharma Co., Ltd., Shanghai, China); fetal bovine serum and 1640 medium (Hyclone; GE Healthcare Life Sciences, Logan, UT, USA); TEM8 antibody (Abcam, Cambridge, UK); Lipofectamine $^{\mathrm{TM}} 2000$ transfection reagent and SYBR Green qPCR SuperMix (Thermo Fisher Scientific Inc., Waltham, MA, USA); Transwell chamber (Corning Incorporated, Corning, NY, USA); vertical electrophoresis and transfer electrophoresis (Bio-Rad Laboratories, Inc., Hercules, CA, USA); ChemiDocTM XRS gel imaging system instrument and TS100 inverted microscope (Nikon Corporation, Tokyo, Japan); fluorescence quantitative polymerase chain reaction (PCR) instrument (Bio-Rad Laboratories, Inc.).

Reverse transcription-quantitative polymerase chain reaction $(R T-q P C R)$. Total RNA was extracted from human lung cancer and adjacent tissues using TRIzol (Invitrogen; Thermo Scientific, Inc.) according to the manufacturer's protocol. RNA purity and quantification were detected by the UV/VIS spectrophotometer (Alpha 1500, Shanghai Puyuan, Shanghai, China). RT was used to synthesize a cDNA (Thermo Scientific, Inc.) for qPCR analysis (Thermo Scientific, Waltham, MA, USA) according to the manufacturer's protocols. The relative expression of TEM8 in each group was detected by RT-qPCR and calculated with GAPDH as internal reference (17). PCR cycling conditions was that initial denaturation at $95^{\circ} \mathrm{C}$ for $5 \mathrm{~min}$; followed by 40 cycles of: denaturation at $95^{\circ} \mathrm{C}$ for $10 \mathrm{sec}$, annealing at $60^{\circ} \mathrm{C}$ for $30 \mathrm{sec}$ and extension at $72^{\circ} \mathrm{C}$ for $30 \mathrm{sec}$. The primes were as follows: GAPDH forward, 5'-TCTCTG CTCCTCCTGTTCGA-3' and reverse, 5'-GCGCCCAATACG ACCAAATC-3'; TEM8 forward, 5'-GCTGCACCACTGGAA
TGAAATCT-3' and reverse, 5'-AGGCCTTGACGGATTTGT TCTCT-3'. The experiment was repeated three times.

Western blot analysis. Lysis buffer (cat. no. C1053+, Beijing PuliLai Gene Technology Co., Ltd, Beijing, China) were added to lung cancer and adjacent tissues. Following $30 \mathrm{~min}$ of lysis, the cells were centrifuged at $1,1180 \mathrm{xg}$ for $20 \mathrm{~min}$ at $4^{\circ} \mathrm{C}$. The supernatant was collected and the total protein was extracted. The concentration of the protein was determined by a bicinchoninic acid assay kit (Beyotime Institute of Biotechnology, Haimen, China), and electrotransferred to a polyvinylidene difluoride membrane following $10 \%$ polyacrylamide gel electrophoresis. About $20 \mu \mathrm{l}$ of protein was loaded per lane. Following blocking for $2 \mathrm{~h}$ at room temperature with $5 \%$ skimmed milk powder, the primary $(1: 1,000$, cat. no. ab21270, Abcam) and horseradish peroxidase labeled goat anti-rabbit IgG H+L secondary antibodies (1:5,000, cat. no. 7074s, Cell Signaling Technology, Inc.) were added, and incubated at room temperature for $2 \mathrm{~h}$. The chemiluminescence method (cat. no. 34077, Thermo Fisher Scientific, Inc.) was used to develop. The optical density of the immunoblotting zone was measured by laser light density scanner. Quantity-One software version 4.62 (Bio-Rad Laboratories, Inc.) was used to analyze the gray value of each antibody band.

Immunohistochemistry. The $4 \mu \mathrm{m}$ thick sections of lung cancer and adjacent tissues were fixed by the $4 \%$ paraformaldehyde for $6 \mathrm{~h}$ at room temperature, dewaxed and dehydrated, washed with water, antigen retrieval was performed in $0.01 \mathrm{~mol} / \mathrm{l}$ citrate buffer ( $\mathrm{pH}$ 6.0) in a microwave oven for $20 \mathrm{~min}$ at $98-100^{\circ} \mathrm{C}$, and blocked using $3 \%$ hydrogen peroxide methanol for $10 \mathrm{~min}$ at room temperature. Finally, they were washed with PBS, incubated with primary antibody with 1:200 dilution (cat. no. ab21270, Abcam) overnight at $4^{\circ} \mathrm{C}$, washed with PBS, which incubated with second antibody with 1:400 dilution (horseradish peroxidase labeled goat anti-rabbit IgG H+L, cat. no. SV2000, Wuhan Boshide health care Biologicals, Co., Ltd., Wuhan, China), washed with PBS, stained with diaminobenzidine for $1 \mathrm{~h}$ at $37^{\circ} \mathrm{C}$, counterstained with hematoxylin for $1 \mathrm{~h}$ at $37^{\circ} \mathrm{C}$, dehydrated, cleared and mounted in gum for microscopic examination. Tan or brown coloration indicated that TEM8 was positively expressed.

Cell transfections. When XWLC-05 cells were confluent to $50-70 \%$, they were transfected with empty vector and TEM8-shRNA (shRNA sequence sense 5'-GGCTAATAG GTCTCGAGATTT-3' and antisense 5'-ATCTCGAGACCT ATTAGCCTT-3') respectively with a Lipofectamine ${ }^{\mathrm{TM}} 2000$ liposome transfection kit (cat. no. 11668027; Thermo Fisher Scientific, Inc.). After 6 h, 1640 medium containing 10\% serum was added, and the cells incubated for $48 \mathrm{~h}$ in a $5 \% \mathrm{CO}_{2}$ incubator. Western blotting and RT-qPCR were used to detect the expression of TEM8 protein and mRNA, as described above.

MTT assay for cell proliferation detection. When cells reached $70 \%$ confluency, in 96-well plates were seeded in a 96-well plate $24 \mathrm{~h}$ following transfection. Fresh medium supplemented with $10 \%$ FBS was added into the plates and to the cells were added $20 \mu \mathrm{l}$ of $5 \mathrm{mg} / \mathrm{ml} \mathrm{MTT}$ at 24, 48, 72 and $96 \mathrm{~h}$ later, respectively, then the cells were further incubated for $4 \mathrm{~h}$. The 
supernatant was discarded, $150 \mu \mathrm{l}$ of DMSO was added per well, and the crystals were dissolved by agitating for $5 \mathrm{~min}$. OD value was measured at $570 \mathrm{~nm}$ by a microplate reader.

Annexin V-PI flow cytometry for cell apoptosis detection. Following cell suspension, $2 \times 10^{5}$ cells were inoculated into 6 -well plates. When cell confluency reached $50-70 \%$, the cells were transfected, as described above. After $48 \mathrm{~h}$, cells were collected and stained (Annexin V-FITC/PI, suolaibao, Beijing, China) in the dark for $30 \mathrm{~min}$. Cell apoptosis was detected by flow cytometry according to Annexin V-FITC/PI kit protocols and analyzed by CellQuest Pro software (BD Biosciences, San Jose, CA, US).

Flow cytometry for cell cycle detection. About $2 \times 10^{5}$ cells were inoculated in 6-well plates and transfected for $48 \mathrm{~h}$. According to the protocols of the cell cycle detection kit (CA1510, suolaibao, Beijing, China), cells were digested by trypsin without EDTA, centrifuged $(1,000 \times \mathrm{g}, 5 \mathrm{~min}$, at room temperature) and suspended. Then $5 \mu \mathrm{l}$ of $10 \mathrm{mg} / \mathrm{ml}$ RNase were added to the cells and they were placed in a water bath at $37^{\circ} \mathrm{C}$ for $1 \mathrm{~h}$, propidium iodide added, stained for $30 \mathrm{~min}$ at room temperature and detected by flow cytometry (FACS Calibur, BD, CA, US) for cell cycle analysis by CellQuest Pro software (BD Biosciences).

Cell scratch assay for cell migration detection. When the cells reached $90 \%$ of confluency following $24 \mathrm{~h}$ of transfection, a $200 \mu \mathrm{l}$ pipette was used to scratch the monolayer cells across the diameter of the wells, the medium and non-adherent cells were aspirated and the plate washed twice with serum-free medium. Then serum-free medium was added. Cells were placed at $37^{\circ} \mathrm{C}$ in $5 \% \mathrm{CO}_{2}$ incubator, and images obtained after 12 and $24 \mathrm{~h}$ using an inverted microscope.

Transwell assay for cell invasion detection. Matrigel was plated onto the microwell in a Transwell chamber. Then the $2 \times 10^{5}$ cells were seeded in the 6 -well plate and transfected when cell fusion reached to $50-70 \%$. Following $48 \mathrm{~h}$ of transfection, the cells were digested and added to Transwell upper chamber and 1640 medium added to the lower chamber. After $48 \mathrm{~h}$, the chamber was removed, fixed with $4 \%$ paraformaldehyde for $30 \mathrm{~min}$ at room temperature and stained with $0.1 \%$ crystal violet for $10 \mathrm{~min}$ at room temperature. Finally, the numbers of cells in 5 visual fields were counted by an inverted microscope and their mean was taken, which was deemed the invasion number (magnification x200).

Statistical analysis. The experiments were repeated 3 times. Mean and standard deviation were used to summarize continuous variables. Student's t-test and one-way analysis of variance were used to determine the differences among groups. Kaplan-Meier method was used to estimate survival rates. $\mathrm{P}<0.05$ was considered to indicate a statistically significant difference. All analyses were performed using SPSS software, version 17.0 (SPSS, Inc., Chicago, IL, USA).

\section{Results}

Level of TEM8 $\mathrm{mRNA}$ and protein for lung cancer and adjacent tissues. The level of TEM8 mRNA expression in lung cancer

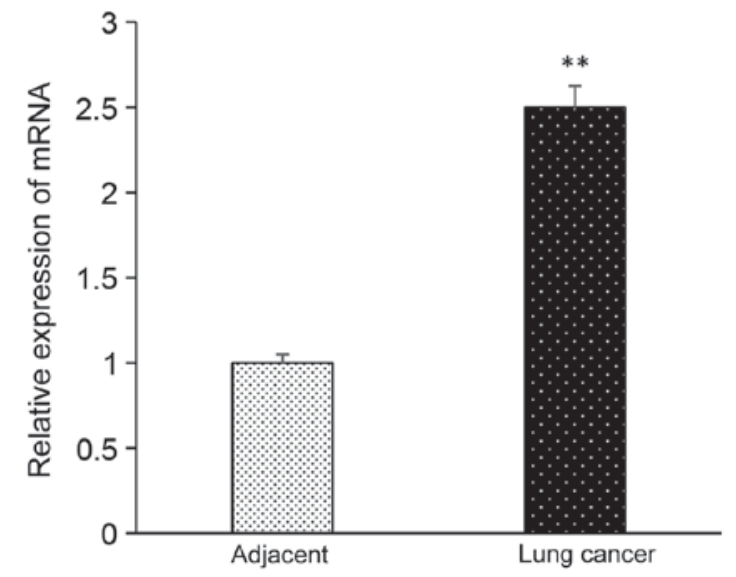

Figure 1. Expression of TEM8 mRNA in adjacent and lung cancer tissues. ${ }^{* * *} \mathrm{P}<0.05$ vs. adjacent group. TEM8, tumor endothelial marker 8 . The experiment was repeated three times.

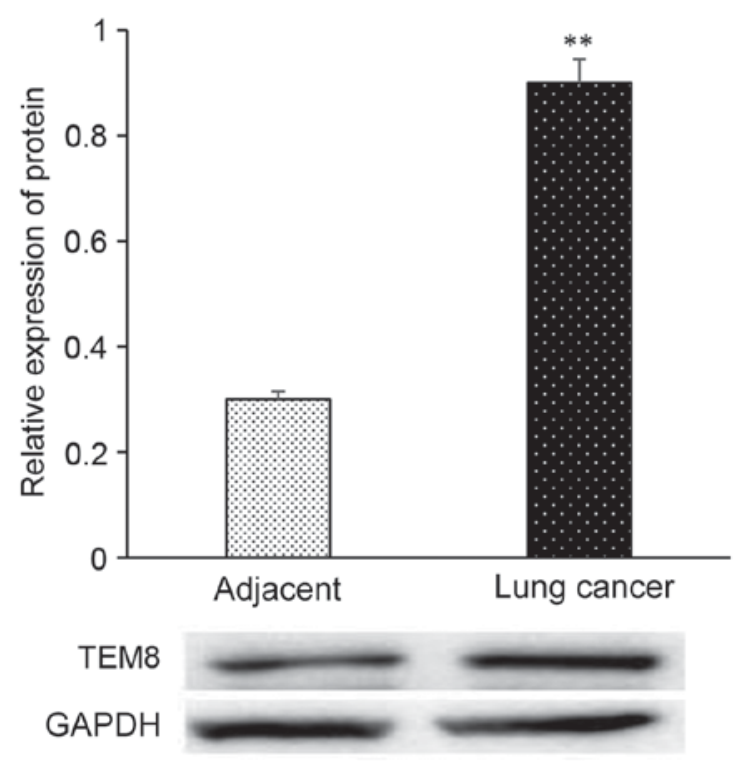

Figure 2. Expression of TEM8 protein in adjacent and lung cancer tissues. ${ }^{* *} \mathrm{P}<0.05$ vs. adjacent group. TEM8, tumor endothelial marker 8 . GAPDH was used as loading control. The experiment was repeated three times.

tissues was significantly higher compared with adjacent tissues as analyzed by RT-qPCR ( $<<0.05$; Fig. 1$)$. The expression level of TEM8 protein in lung cancer tissues was significantly higher than that in adjacent tissues as analyzed by western blotting ( $\mathrm{P}<0.05$; Fig. 2). In Fig. 3, the brown color represented TEM8 protein expression, which seems to be higher in lung cancer tissues compared with adjacent tissues, although this lacks quantification.

Level of TEM8 mRNA and protein for XWLC-05 transfection of lung cancer cells. Compared with the control group, the expression level of TEM8 was significantly reduced in XWLC-05 cells transfected with TEM8-shRNA as measured by RT-qPCR ( $\mathrm{P}<0.05 ;$ Fig. 4). Compared with the control group, the expression level of TEM8 protein, as presented in Fig. 5, was significantly decreased in the transfected TEM8-shRNA group $(\mathrm{P}<0.05)$ 
A

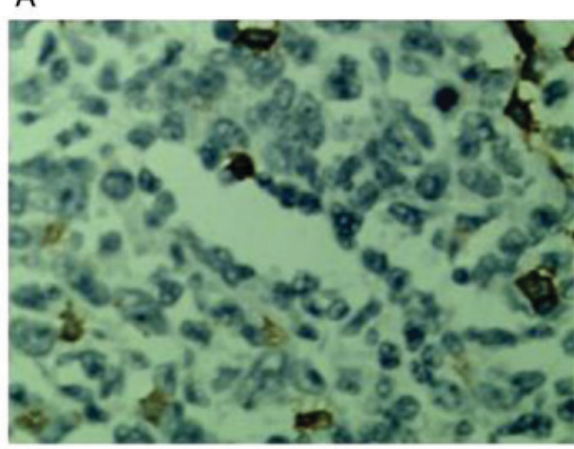

B

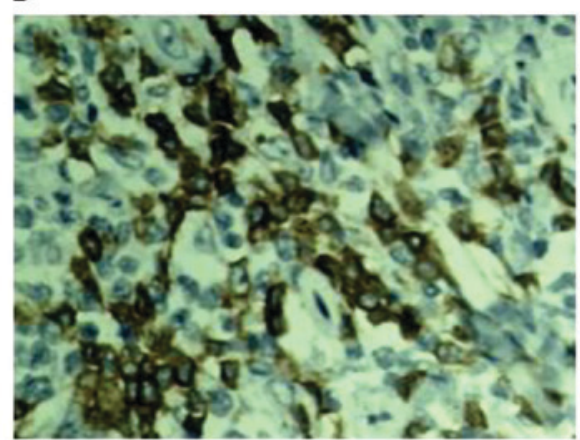

Figure 3. Immunohistochemistry of tumor endothelial marker 8 protein expression of in (A) adjacent and (B) lung cancer tissues. Magnification, x200.

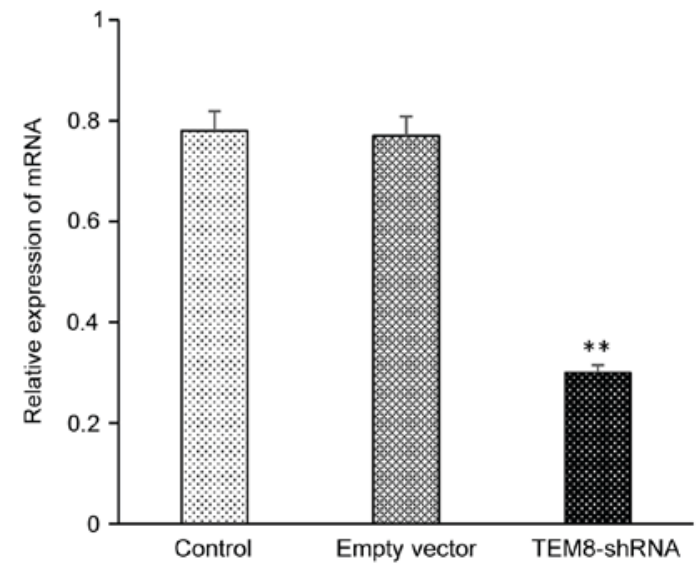

Figure 4. Expression of TEM8 mRNA in the control group, empty vector group and TEM8-shRNA group. ${ }^{* *} \mathrm{P}<0.05$ vs. control. TEM8, tumor endothelial marker 8; shRNA, short hairpin RNA. The experiment was repeated three times.

Effect of silencing TEM8 on the proliferation and apoptosis of XWLC-05 lung cancer cells. MTT results suggested that the proliferation of TEM8-shRNA group was significantly lowered compared with the control group at 48,72 and $96 \mathrm{~h}$, respectively ( $\mathrm{P}<0.05$; Fig. 6). Annexin V-FITC/PI staining revealed that the apoptotic rate of TEM8-shRNA group cells was significantly higher compared with the control group $(\mathrm{P}<0.05$; Fig. 7).

Effect of silencing TEM8 on the migration and invasion of XWLC-05 lung cancer cells. As demonstrated in Fig. 8, the result of cell scoring in vitro revealed that following the silencing of TEM8, the migration ability of XWLC-05 cells was significantly decreased compared with the control group. Transwell invasion assay indicated that the invasion number of cells per field in TEM8-shRNA group $(40.25 \pm 3.02)$ was significantly lower compared with the control group $(129.39 \pm 9.69$; $\mathrm{P}<0.05$; Fig. 9).

Effect of silencing TEM8 on the cell cycle of lung cancer cell XWLC-05. Fig. 10 and Table I demonstrate that more cells were detected in G1 phase and fewer in S phase in the TME-8-shRNA group compared to the control group or empty group $(\mathrm{P}<0.05)$ while no significant differences were observed in $\mathrm{G} 2$ phase among the three groups, suggesting that silencing TEM8 blocked the cell cycle of XWLC-05 cells at G1 phase.

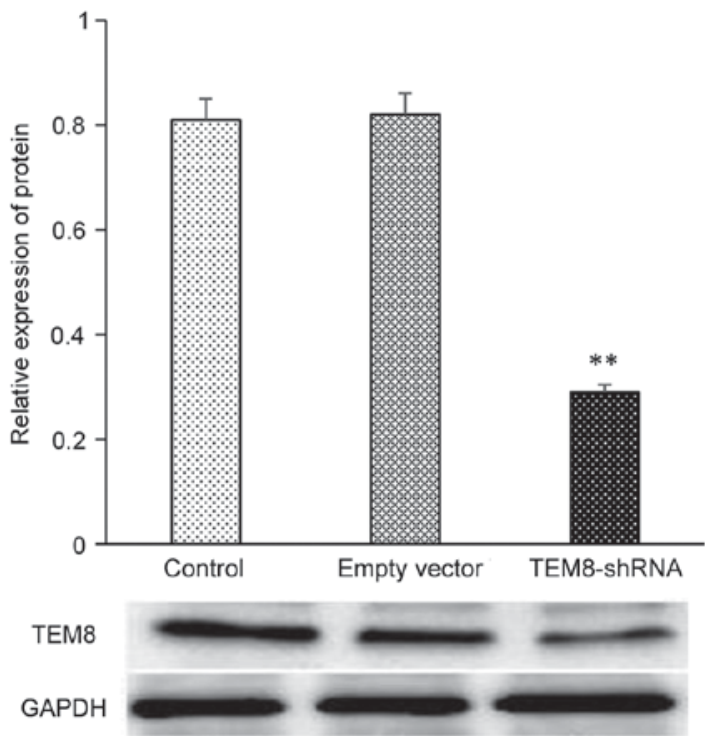

Figure 5. Expression of TEM8 protein in the control group, empty vector group and TEM8-shRNA group. ${ }^{* *} \mathrm{P}<0.05$ vs. control. TEM8, tumor endothelial marker 8; shRNA, short hairpin RNA. The experiment was repeated three times.

\section{Discussion}

The incidence of lung cancer is increasing with the aging of populations, pollution of the environment and abuse of tobacco products, and has become a malignancy with the highest mortality $(18,19)$. In the past few decades, although there have been a number of new treatments including new chemotherapy drugs, tyrosine kinase inhibitor medications, immunotherapy and anti-angiogenic therapy, the survival rate of lung cancer has not improved significantly $(20,21)$. In order to make a breakthrough in therapy and overall survival, it is necessary to possess an in depth understanding of the occurrence and development of lung cancer.

Angiogenesis is necessary in physiological processes including embryonic development, wound healing and tissue regeneration. However, angiogenesis also implicated in the pathological process of malignant transformation. Anti-tumor angiogenesis has become an important area in cancer research. Tumor angiogenesis serves an important role in processes of tumorigenesis, tumor progression, invasion and metastasis. Circulation within tumor tissues provides 
Table I. Effect of silenced TEM8 on the cell cycle of XWLC-05 lung cancer cells.

\begin{tabular}{lccc}
\hline Group & G1 phase & S phase & G2 phase \\
\hline Control & $36.10 \pm 4.12$ & $59.70 \pm 5.36$ & $4.20 \pm 1.01$ \\
Empty vector & $37.43 \pm 4.23$ & $58.11 \pm 5.14$ & $4.45 \pm 1.09$ \\
TEM8-shRNA & $54.10 \pm 6.25^{\mathrm{a}}$ & $40.80 \pm 4.58^{\mathrm{a}}$ & $5.10 \pm 1.24$
\end{tabular}

${ }^{\mathrm{a}} \mathrm{P}<0.05$. TEM8, tumor endothelial marker 8; shRNA, short hairpin RNA.

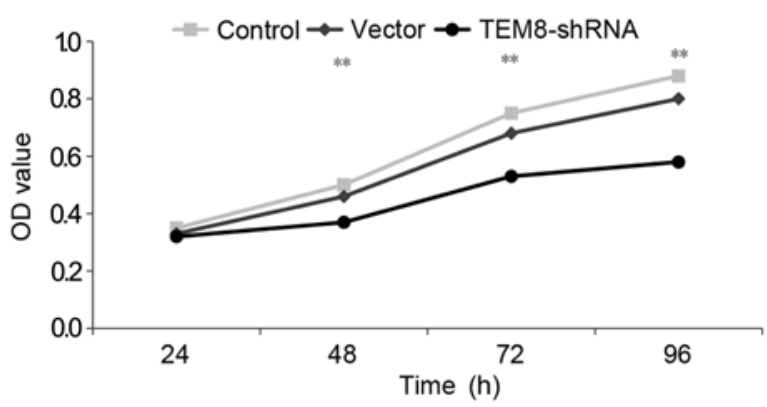

Figure 6. Effect of silencing TEM8 on the viability of lung cancer cell XWLC-05. ${ }^{* *} \mathrm{P}<0.05$ vs. control. TEM8, tumor endothelial marker 8; shRNA, short hairpin RNA. The experiment was repeated three times.

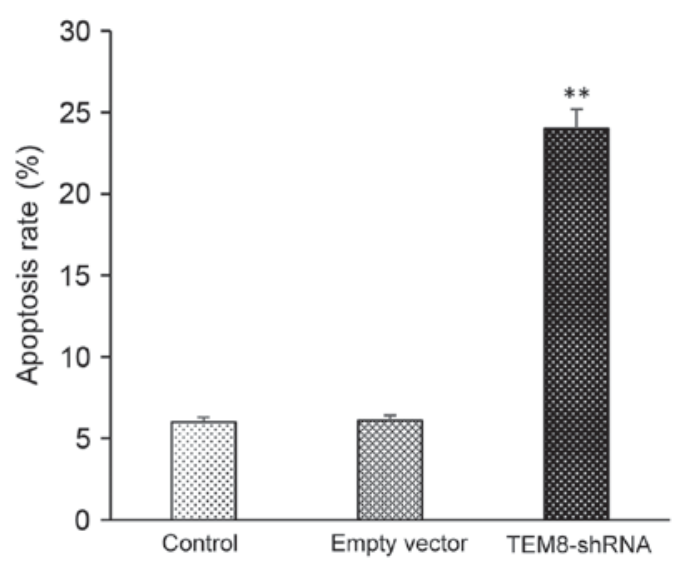

Figure 7. The cell apoptosis rate of control group, empty vector group and TEM8-shRNA group. ${ }^{* *} \mathrm{P}<0.05$ vs. control group. TEM8, tumor endothelial marker 8; shRNA, short hairpin RNA. The experiment was repeated three times.

nutrition for tumor cells while excreting metabolic products. Furthermore, the tumor vascular wall is often incomplete, which benefits tumor cells by enabling them to penetrate through the wall into vessels, causing hematogenous metastasis. Considering the important role of angiogenesis in tumor growth, disrupting tumor angiogenesis may starve the tumor of nutrition and halt development (22). The pathway of angiogenesis can be blocked through the regulation of angiogenesis and promoting factors. The inhibition of tumor angiogenesis can control tumor growth, in theory, with tumor endothelial molecular markers or high growth state as the target.
Inhibition of tumor angiogenesis has become one of the main strategies for cancer treatment, with vascular endothelial growth factor (VEGF) as a pro-angiogenic factor of high specificity (23). Compared with the normal tissue, VEGF and its receptor expression level are significantly increased in tumor tissue (24). Various drugs targeted at VEGF and its receptor have been widely applied, including Avastin (25), sorafenib (26), sunitinib (27), Endostar (28) and Apatinib (29). Studies have demonstrated that these drugs can extend the survival time of advance colorectal, gastric, and lung cancers when combined with radiotherapy and/or chemotherapy.

However, the overall efficacy of anti-tumor angiogenesis treatments has not reached the original high expectations. They only minimally improve symptoms and extend the remission, without significant improvement on overall survival rates. The majority of endothelial markers are expressed in tumors and normal tissues, making it difficult to specifically target tumor endothelium, and likely to cause adverse reactions and widespread drug resistance. There tends to be 'resilient growth' following discontinuation of short-term anti-angiogenic treatments, which increases the risk of tumor recurrence and metastasis. Therefore, finding more specific markers of tumor blood vessels serves an important role in understanding the mechanism of anti-tumor vascular therapy and clinical application.

The extracellular domain of TEM8 has a von Willebrand factor (vWF) domain, which is high homology with integrin $9 \alpha 2$ (29). As with integrin, vWF has a metal ion dependent adhesion sequence (30). A decline in the expression of integrin increases the invasion ability of tumor cells (31). Studies on colorectal cancer by Rmali et al (32) and St Croix et al (15) identified that TEM8 was expressed highly in cancerous tissue but very low in adjacent and normal tissue, indicating that TEM8 may serve a role in promoting cancer.

The present study used RT-qPCR, western blot analysis and immunohistochemistry to detect the levels of TEM8 mRNA and protein in lung cancer tissue and adjacent tissue, identifying that TEM8 expresses highly in lung cancer tissue and had trace expression in adjacent tissues. A TEM8 interference vector was transfected into XWLC-05 lung cancer cells. Compared with the control group, cells transfected with TEM8-shRNA expressed less TEM8, as measured by RT-qPCR and western blot analysis, demonstrating that the shRNA silenced TEM8. The influence that TEM8 knockdown had on XWLC-05 activity and apoptosis demonstrated that silenced TEM8 could reduce XWLC-05 lung cancer cell viability and increase its rate of apoptosis. The results of the cell cycle experiment demonstrated that TEM8 knockdown blocked cell cycle progression at the G1 phase, and results of the Transwell assay demonstrated that TEM8 silencing decreased the invasion ability of XWLC-05, indicating that silenced TEM8 can reduce the cell viability of XWLC-05, induce apoptosis, block the cell cycle at G1 phase and inhibit the invasive ability.

In summary, TEM8 expression is increased in lung cancer tissues compared with normal tissue. The activity of XWLC-05 cells was decreased and the cell cycle was blocked at G1 phase following silencing of TEM8, inhibiting the cell invasion ability. TEM8 may become a target for antitumor therapy and potentially is involved in tumor angiogenesis. 
A
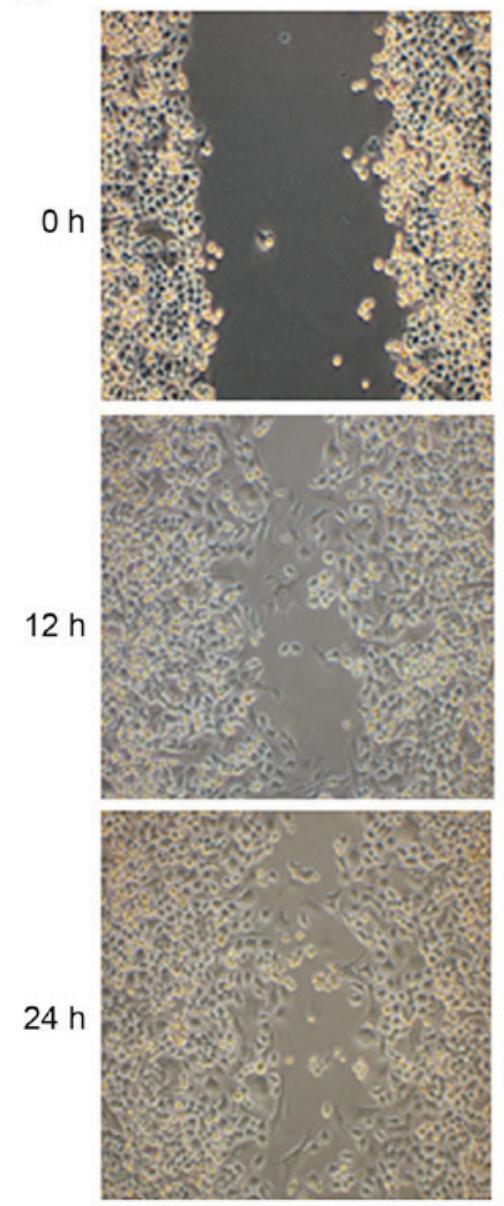

B
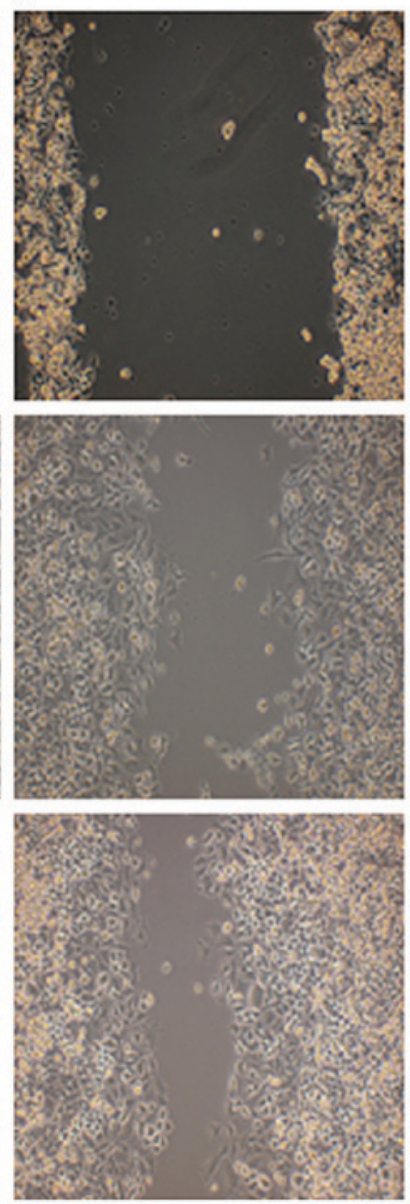

C
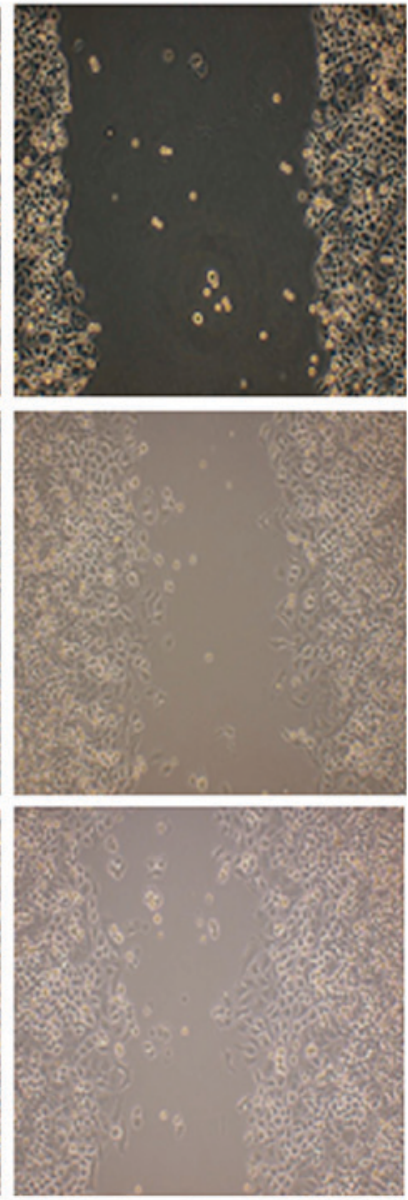

Figure 8. Migration ability of XWLC-05 cells of the (A) control group, (B) empty vector group and (C) TEM8-shRNA group. TEM8, tumor endothelial marker 8; shRNA, short hairpin RNA. Magnification, $\mathrm{x} 100$. The experiment was repeated three times.

A

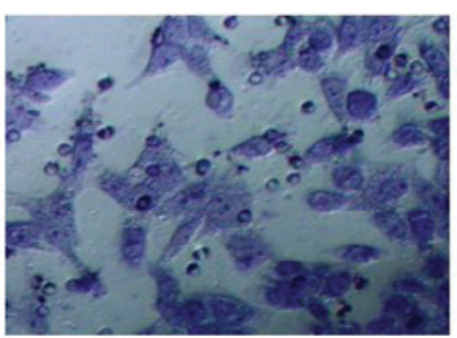

B

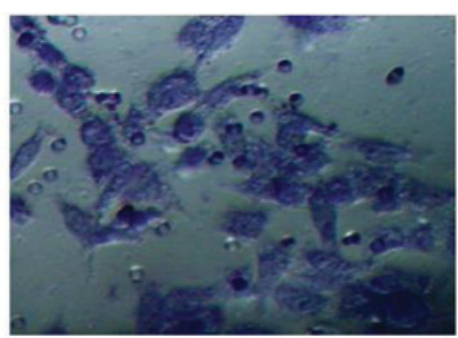

C

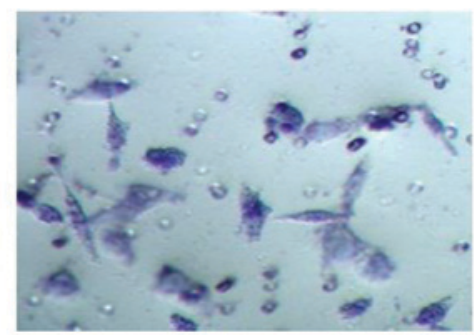

Figure 9. Invasion ability of (A) control group, (B) empty vector group and (C) TEM8-shRNA group, as assessed by $0.1 \%$ crystal violet staining. TEM 8 , tumor endothelial marker 8; shRNA, short hairpin RNA. Magnification, x200.
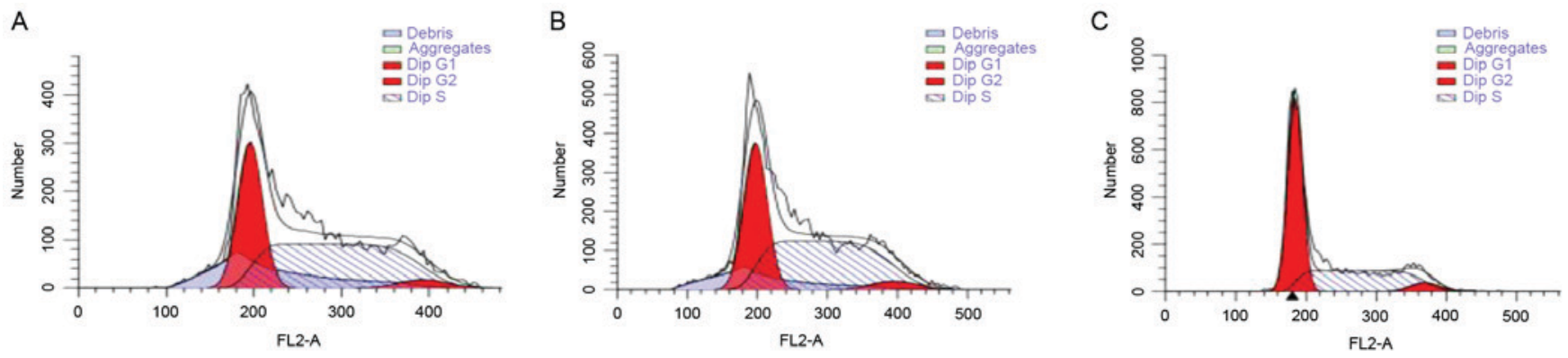

Figure 10. Cell cycle analysis of (A) control group, (B) empty vector group and (C) TEM8-shRNA group cells. TEM8, tumor endothelial marker 8; shRNA, short hairpin RNA. The experiment was repeated three times. 


\section{Acknowledgements}

The present study was supported by the National Natural Science Foundation of China (grant nos. 81460358 and 81060177) and Health Science and Technology Project of Yunnan Province (grant nos. 2014NS027 and 2016NS098).

\section{References}

1. Jemal A, Bray F, Center MM, Ferlay J, Ward E and Forman D: Global cancer statistics. CA Cancer J Clin 61: 69-90, 2011.

2. Parkin DM, Bray F, Ferlay J and Pisani P: Global cancer statistics, 2002. CA Cancer J Clin 55: 74-108, 2005.

3. Bergers $G$ and Hanahan D: Modes of resistance to anti-angiogenic therapy. Nat Rev Cancer 8: 592-603, 2008.

4. Clarke JM and Hurwitz HI: Understanding and targeting resistance to anti-angiogenic therapies. J Gastrointest Oncol 4 253-263, 2013.

5. Gacche RN and Meshram RJ: Angiogenic factors as potential drug target: Efficacy and limitations of anti-angiogenic therapy. Biochim Biophys Acta 1846: 161-179, 2014.

6. Ebos JM,Lee CR, Cruz-Munoz W, Bjarnason GA, Christensen JG and Kerbel RS: Accelerated metastasis after short-term treatment with a potent inhibitor of tumor angiogenesis. Cancer Cell 15: 232-239, 2009

7. Presta M, Dell'Era MP, Mitola S, Moroni E, Ronca R and Rusnati M: Fibroblast growth factor/fibroblast growth factor receptor system in angiogenesis. Cytokine Growth Factor Rev 16: 159-178, 2005.

8. Kamba T and McDonald DM: Mechanisms of adverse effects of anti-VEGF therapy for cancer. Br J Cancer 96: 1788-1795, 2007.

9. Kubota Y: Tumor angiogenesis and anti-angiogenic therapy. Keio J Med 61: 47-56, 2012.

10. Verheul HM and Pinedo HM: Possible molecular mechanisms involved in the toxicity of angiogenesis inhibition. Nat Rev Cancer 7: 475-485, 2007.

11. Tartari RF, Ulbrich-Kulczynski JM and Filho AF: Measurement of mid-arm muscle circumference and prognosis in stage IV non-small cell lung cancer patients. Oncol Lett 5: 1063-1067, 2013.

12. Shimizu T, Yokoi T, Tamaki T, Kibata K, Inagaki $\mathrm{N}$ and Nomura S: Comparative analysis of carboplatin and paclitaxel combination chemotherapy schedules in previously untreated patients with advanced non-small cell lung cancer. Oncol Lett 5: 761-767, 2013.

13. Mutlu H, Buyukcelik A, Kaya E, Kibar M, Seyrek E, Yavuz S and Calikusu Z: Sunlight may increase the FDG uptake value in primary tumors of patients with non-small cell lung cancer. Oncol Lett 5: 773-776, 2013.

14. Yan FC, Wang QQ, Ruan YH, Ma LJ, Jia JT and Jin KW: Establishment and biological characteristics of lung cancer cell line XWLC-05. Ai Zheng 26: 21-25, 2007 (In Chinese).

15. St Croix CM, Morgan BJ, Wetter TJ and Dempsey JA: Fatiguing inspiratory muscle work causes reflex sympathetic activation in humans. J Physiol 529: 493-504, 2000.

16. Hotchkiss KA, Basile CM, Spring SC, Bonuccelli G, Lisanti MP and Terman BI: TEM8 expression stimulates endothelial cell adhesion and migration by regulating cell-matrix interactions on collagen. Exp Cell Res 305: 133-144, 2005.

17. Livak KJ and Schmittgen TD: Analysis of relative gene expression data using real-time quantitative PCR and the 2(-Delta Delta C(T)) method. Methods 25: 402-408, 2001.

18. She J, Yang P, Hong Q and Bai C: Lung cancer in China: Challenges and interventions. Chest 143: 1117-1126, 2013.
19. Wang L, Zhu LP and Wang X: Incidence and mortality of lung cancer among residents covered by cancer registry system in Jiangxi province, 2011-2013. Chin J Public Health 32: 654-657, 2016.

20. Reichardt P, Blay JY, Gelderblom H, Schlemmer M, Demetri GD, Bui-Nguyen B, McArthur GA, Yazji S, Hsu Y, Galetic I and Rutkowski P: Phase III study of nilotinib versus best supportive care with or without a TKI in patients with gastrointestinal stromal tumors resistant to or intolerant of imatinib and sunitinib. Ann Oncol 23: 1680-1687, 2012.

21. Cross DA, Ashton SE, Ghiorghiu S, Eberlein C, Nebhan CA, Spitzler PJ, Orme JP, Finlay MR, Ward RA, Mellor MJ, et al: AZD9291, an irreversible EGFR TKI, overcomes T790M-mediated resistance to EGFR inhibitors in lung cancer. Cancer Discov 4: 1046-1061, 2014.

22. Lee TT, García JR, Paez JI, Singh A, Phelps EA, Weis S, Shafiq Z, Shekaran A, Del Campo A and García AJ: Light-triggered in vivo activation of adhesive peptides regulates cell adhesion, inflammation and vascularization of biomaterials. Nat Mater 14: 352-360, 2015.

23. Möller B, Rasmussen C, Lindblom B and Olovsson M: Expression of the angiogenic growth factors VEGF, FGF-2, EGF and their receptors in normal human endometrium during the menstrual cycle. Mol Hum Reprod 7: 65-72, 2001.

24. Kim DH, Sung B, Kang YJ, Hwang SY, Kim MJ, Yoon JH, Im E and Kim ND: Sulforaphane inhibits hypoxia-induced HIF-1a and VEGF expression and migration of human colon cancer cells. Int J Oncol 47: 2226-2232, 2015.

25. Yang JC, Haworth L, Sherry RM, Hwu P, Schwartzentruber DJ, Topalian SL, Steinberg SM, Chen HX and Rosenberg SA: A randomized trial of bevacizumab, an anti-vascular endothelial growth factor antibody, for metastatic renal cancer. N Engl J Med 349: 427-434, 2003.

26. Cainap C, Qin S, Huang WT, Chung IJ, Pan H, Cheng Y, Kudo M, Kang YK, Chen PJ, Toh HC, et al: Linifanib versus Sorafenib in patients with advanced hepatocellular carcinoma: Results of a randomized phase III trial. J Clin Oncol 33: 172-179, 2015.

27. Tannir NM, Jonasch E, Albiges L, Altinmakas E, Ng CS, Matin SF, Wang X, Qiao W, Dubauskas Lim Z, Tamboli P, et al: Everolimus versus sunitinib prospective evaluation in metastatic non-clear cell renal cell carcinoma (ESPN): A randomized multicenter phase 2 trial. Eur Urol 69: 866-874, 2016.

28. Tang H, Ma H, Peng F, Bao Y, Hu X, Wang J, Xu Y and Chen M: Prognostic performance of inflammation-based prognostic indices in locally advanced non-small-lung cancer treated with endostar and concurrent chemoradiotherapy. Mol Clin Oncol 4: 801-806, 2016.

29. Li J, Qin S, Xu J, Xiong J, Wu C, Bai Y, Liu W, Tong J, Liu Y, $\mathrm{Xu}$, et al: Randomized, double-blind, placebo-controlled phase iii trial of apatinib in patients with chemotherapyrefractory advanced or metastatic adenocarcinoma of the stomach or gastroesophageal junction. J Clin Oncol 34: 1448-1454, 2016

30. Whittaker CA and Hynes RO: Distribution and evolution of von Willebrand/integrin A domains: Widely dispersed domains with roles in cell adhesion and elsewhere. Mol Biol Cell 13: 3369-3387, 2002.

31. Hood JD and Cheresh DA: Role of integrins in cell invasion and migration. Nat Rev Cancer 2: 91-100, 2002.

32. Rmali KA, Puntis MC and Jiang WG: Prognostic values of tumor endothelial markers in patients with colorectal cancer. World $\mathbf{J}$ Gastroenterol 11: 1283-1286, 2005.

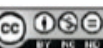

licensed under a Creative Commons Attribution-NonCommercial-NoDerivatives 4.0 International (CC BY-NC-ND 4.0) License. 